\title{
Protoporphyrin IX
}

National Cancer Institute

\section{Source}

National Cancer Institute. Protoporphyrin IX. NCI Thesaurus. Code C785.

A tetrapyrrole containing 4 methyl, 2 propionic and 2 vinyl side chains that is a metabolic precursor for hemes, cytochrome c and chlorophyll. Protoporphyrin IX is produced by oxidation of the methylene bridge of protoporphyrinogen by the enzyme protoporphyrinogen oxidase. 